\title{
LA RUTA INCA A LOS HUAYLAS. ESTUDIO DE LA VIALIDAD INCA EN LA PAMPA DE LAMPAS-CHOQUERECUAY, EN EL DEPARTAMENTO DE ANCASH, PERÚ
}

\author{
THE INCA ROUTE TO THE HUAYLAS. A STUDY OF INCA ROADS IN PAMPA \\ DE LAMPAS, CHOQUERECUAY, DEPARTMENT OF ANCASH, PERÚ
}

JOSEPH BERNABÉA

En este trabajo se presenta el registro de la red vial inca en la pampa de Lampas, región ubicada al sur del callejón de Huaylas, en el lado occidental de la cordillera Blanca en la Región Ancash. Para ello, se recurre al análisis del registro arqueológico, producto de trabajos de campo desarrollados por el Proyecto Qhapaq Ñan en sus temporadas 2003 y 2004, así como la actualización de información, que tuvo como punto de inicio el análisis de imágenes satelitales. Esto llevó a realizar nuevos trabajos de campo los años 2014 y 2015 para registrar las características formales de la vialidad y realizar el levantamiento planimétrico de los sitios asociados a los caminos. La revisión de fuentes bibliográficas, arqueológicas e históricas nos ha permitido desarrollar el presente estudio.

Palabras clave: caminos, pachacoto, ushnu, kancha, pampa de lampas, Choquerecuay.

This work presents the information documented for the Inca road network in the Lampas Pampa, a zone located south of Callejón de Huaylas, on the western side of the Cordillera Blanca of Ancash Region. The authors analyse the archeological records collected by the Qhapaq Nan Project in the 2003 and 2004 fieldwork seasons, as well as updates based first on an analysis of satellite images then expanded during fieldwork in 2014 and 2015 to record the formal features of the roadways and the elaboration of a planmetric survey of associated sites. A review of bibliographic, archeological and historical sources enhanced the study conducted.

Keywords: roads, Pachacoto, ushnu, kancha, pampa of Lampas, Choquerecuay.

\section{INTRODUCCIÓN}

La red vial inca o camino principal andino nacía en la plaza Haucaypata, en el centro del Cusco, proyectándose mediante un trazo longitudinal de sur a norte hacia el Chinchaysuyu y de norte a sur hacia el Collasuyu; y dos caminos transversales, uno hacia el oriente: el Antisuyu, y otro al occidente: el Cuntisuyu. El camino se materializaba mediante una red vial perfectamente constituida que comunicaba nodos de conexión o centros administrativos, permitiendo la administración y control de regiones culturalmente diferentes a la nación cusqueña.

Esta extensa red vial de uso pedestre permitía el desplazamiento de funcionarios cusqueños y locales, ejércitos, mitmaq, capacochas, caravanas de camélidos que transportaban bienes de producción y otros especialistas al servicio del Estado. Todos ellos se movilizaban por motivos estrictamente oficiales de índole política, económica, militar y religiosa. Su construcción y mantenimiento dependió de instituciones públicas y fuerza de trabajo obtenida de grupos mitmacunas.

El aparato estatal instituyó los tambos, establecimientos estratégicamente ubicados a la vera del cami-

\footnotetext{
A Joseph Bernabé, Proyecto Qhapaq Nan, Perú / Ministerio de Cultura. Av. Javier Prado Este 2465 San Borja, Lima 41, Perú, email: josephberna@hotmail.com
} 
no que facilitaban el abastecimiento de las comitivas oficiales y de los ejércitos, a la vez que se construyeron elementos arquitectónicos sobre las principales rutas: plataformas, marcadores, puentes colgantes, calzadas empedradas, lo que sumado al desarrollo de diferentes técnicas, permitió su sostenimiento y funcionamiento.

Precisamente, este trabajo presenta los resultados preliminares de un estudio sobre la vialidad inca en el Departamento de Ancash, en el marco del Proyecto Qhapaq Nan. Para este fin, se ha utilizado la información obtenida de los reconocimientos de campo realizados entre 2003 y 2004, de los tramos de caminos prehispánicos y sus componentes asociados. Al mismo tiempo, se han revisado fuentes históricas, informes de investigación, material cartográfico y aerofotográfico, así como el análisis de imágenes satelitales mediante la plataforma Google Earth. Dicha información ha permitido actualizar y precisar la data de campo.

\section{ÁREA DE ESTUDIO}

El ámbito de estudio se ubica en el extremo sur de Callejón de Huaylas, en la jurisdicción de la provincia de Bolognesi y Recuay, en el departamento de Ancash. El área comprende una gran meseta altoandina conocida como las pampas de Lampas (4050 msnm, fig. 1) y Pachacoto (3900 msnm). La proyección de la vialidad inca en esta región abarca un subtramo de $62 \mathrm{~km}$ de longitud, el cual formó parte del camino longitudinal de la sierra.

Geográficamente, el área de estudio se enmarca en la cuenca alta del río Santa, donde destaca la región la quechua (3000 msnm), jalca o la suni (3500 msnm), puna (4000 msnm) y la janca o cordillera Nevada (4800 msnm) (Pulgar 1967). La red vial inca se emplaza entre las tres primeras regiones naturales y, en mayor porcentaje, en la región puna. Esta región se encuentra formada por grandes estepas y zonas inundables como bofedales, arroyos y lagunas que se originan de los glaciares ubicados en el lado occidental de la cordillera Blanca.

\section{Antecedentes históricos}

La importancia de este subtramo Lampas-Choquerecuay se describe en las primeras fuentes históricas, entre ellas la escrita por Miguel de Estete, en la relación del viaje que hizo Hernando Pizarro de Cajamarca al Santuario de Pachacamac, en enero de $1534 .{ }^{3}$ Estete menciona los lugares principales por donde transitaron, llegando a "Guarax" el 24 de enero siendo recibidos por el señor Pumacapillay, continuando hacia "Sucoarocoay", prosiguiendo hasta Pachacoto el 25 de enero, donde tomaran el camino que baja a la costa por "Marcara" (Marca) y el valle de Fortaleza hasta Paramonga; allí tomaron la ruta del camino costero rumbo al valle de Lurín. En esta relación se hace mención de los principales asentamientos asociados a la vialidad inca en nuestra área de estudio, como Sucorecuay (Choquerecuay o Pueblo Viejo) y Pachacoto.

En agosto del mismo año, Francisco Pizarro realizó la marcha de Cajamarca al Cusco, tomando el mismo trayecto que su hermano Hernando Pizarro. Cruzó la Provincia inca de Huaylas, donde permaneció aproximadamente 12 días entre Tocas y Recuay (Zuloaga 2011: 70), continuó por Pachacoto hacia Cajatambo, tramo en el que debió cruzar la pampa de Lampas. En estas primeras incursiones hispanas al centro del Tawantinsuyu se utilizó un ramal del Qhapaq Ñan que se proyectaba por todo el Callejón de Huaylas, aprovechado estratégicamente por la alta densidad demográfica asentada a la vera del camino. Esto permitió el abastecimiento de alimentos y un mayor conocimiento acerca de la organización política y social del Estado Inca (Del Busto 1999: 24).

\section{La conquista inca a los Huaylas}

La vialidad inca no solo logró la integración y control de las cabeceras de la cuenca alta del río Santa, sino que también abarcó las cuencas bajas de los ríos: Huaura, Pativilca, Fortaleza, Huarmey y Casma, anexando a un abigarrado conjunto de grupos étnicos de habla quechua ubicados sobre ambas márgenes de la cordillera Blanca y Negra en la Provincia inca de Huaylas. Durante el Horizonte Tardío (1470), toda esta región estuvo anexada política y administrativamente al Estado Inca, teniendo como eje integrador una variante del camino longitudinal de la sierra, que nacía en el centro administrativo de Pumpu (Pasco) y continuaba con rumbo noroeste hacia el Callejón de Huaylas.

Esta vasta región, que integró los grupos étnicos de Lampas y Huaylas, fue conquistada por el Inca Pachacutec a mediados del siglo xv, quien encomendó a su hermano Inca Capac Yupanqui la dirección de la expedición que consiguió dominar a los Huanca, Huarochiri, Yauyo, Chucurpu, Atapillo, Canta, Tarma, Chinchaycocha, Checra, Cajatambo y Lampacollana (Robles 2003: 116). 


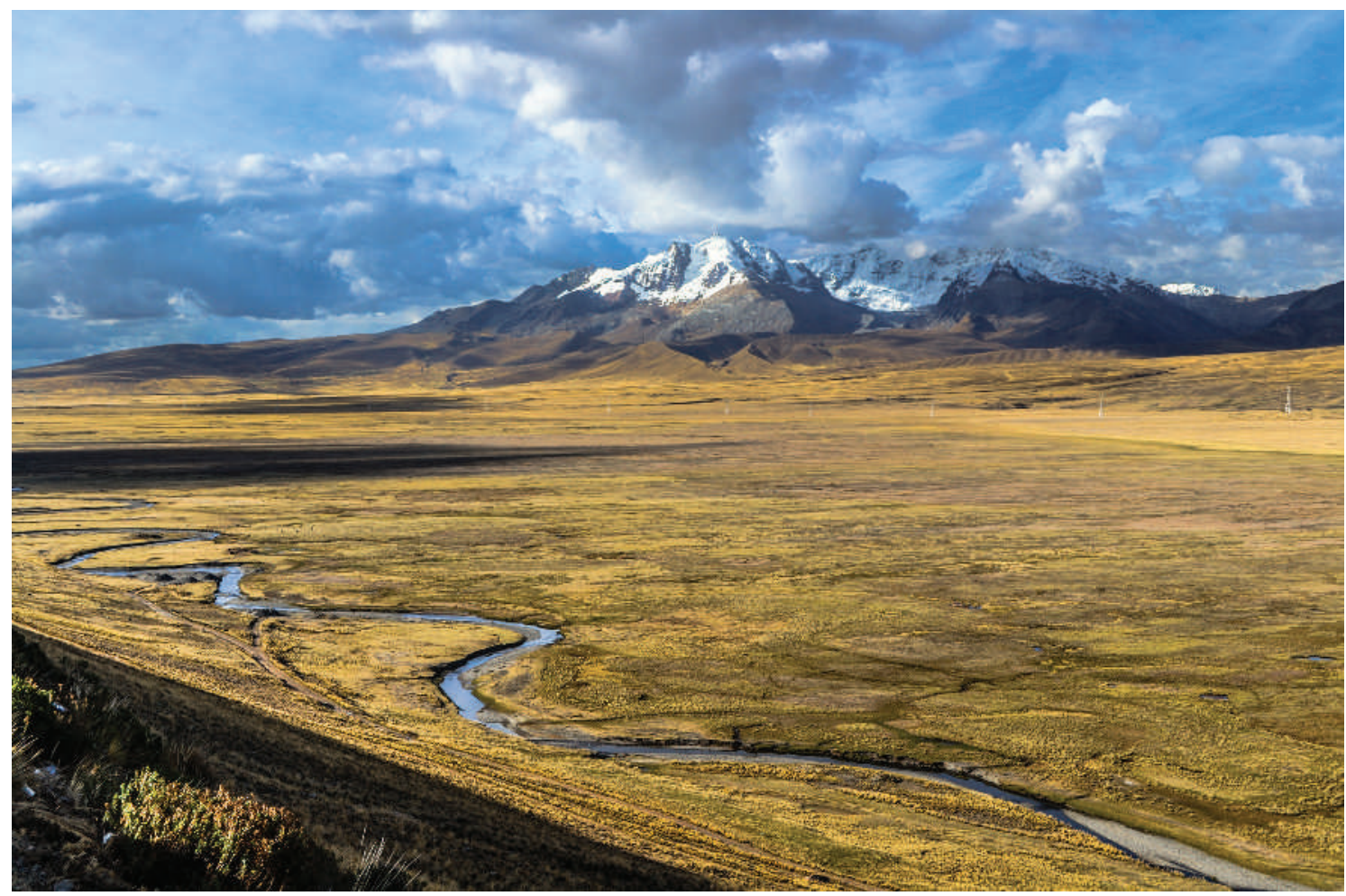

Figura 1. Vista de la pampa de Lampas teniendo en segundo plano el nevado Jeulla Rajo. Figure 1. View of the pampa of Lampas with Jeulla Rajo in the background.

La primera expedición conquistó dos provincias extensas y de alta demografía llamadas Ancara y Huaillas. Si embargo, esto no fue suficiente para asegurar el control sobre los pueblos de Huaylas, por lo que Pachacuti Inca envió nuevamente a su hermano, acompañado esta vez por el hijo y sucesor de Pachacuti, Inca Yupanqui quien tenía 16 años, y un ejército de 50.000 hombres (Garcilaso 1985 [1609]: 229-230). En esta segunda expedición quedó afianzado el dominio inca sobre la región de los Huaylas, Pincos y Piscobamba (Garcilaso 1985 [1609]: 229-230; Varón 1980: 39).

A la llegada de los hispanos, la provincia de Huaylas se encontraba dividida políticamente en dos mitades: Huringuaylas, en el extremo sur, y Hananguaylas, en el extremo norte. Cada una de ellas se subdividía en seis guarangas (Varón 1980: 40; Zuloaga 2011: 69, 2012). Colindante con la frontera sur de los Huaylas se encontraba la región de Lampas, organizada en tres guarangas: ${ }^{1}$ Collana Guaranga, Chaupi Guaranga y la Guaranga de Ocros (Pereyra 1989: 24). Cada una de estas subdivisiones contaba con un curaca principal y señor de varias guarangas con sus curacas subalternos.
Esta división por guarangas tenía un carácter netamente administrativo, pero con una significación social, económica, ecológica (Varón 1980), a la que hay que añadir la simbólica o religiosa impuesta por los incas. Además, esta división respondía a un aprovechamiento racional de zonas de producción, tales como los extensos pastizales de la pampa de Lampas aptos para la crianza de camélidos.

La conquista inca provocó cambios a gran escala, los que implicaron la restructuración de la organización política regional y local, entre ellos, la incorporación a una nueva demarcación administrativa con patrones externos, tales como la estructura hanan y hurin; la reordenación del espacio y del acceso a los recursos; la imposición de dioses regionales (provinciales) y estatales (el sol); la introducción de autoridades políticas y regionales jerárquicamente superiores a los locales; el traslado masivo de poblaciones locales y, finalmente, la creación de la Provincia inca de Huaylas.

La Provincia inca de Huaylas mantuvo su estructura local de producción, pero integrándola a la economía estatal a través de los diversos depósitos y caminos que 
se construyeron a la vera de la ruta principal, y la suma de un nivel superior de reciprocidad con el gobernante Inca. Huaylas pasó a depender administrativamente de Huánuco Pampa, y se instaló una capital provincial de menor jerarquía ubicada en el extremo norte del Callejón de Huaylas, en las inmediaciones del actual pueblo de Huaylas, denominada como Hatun Huaylas ${ }^{2}$ (Varón 1980: 42). Al extremo sur, en la región de hurinhuaylas se estableció otra cabeza de provincia que tuvo como centro de poder el asentamiento inca de Sucoarecuay o Choquerecuay (Zuloaga 2012).

\section{ESTUDIO DE LA VIALIDAD INCA ENTRE LAMPAS-CHOQUERRECUAY}

En mérito al Decreto Supremo $N^{\circ}$ 031-2001-ED, el Estado peruano declaró de interés nacional el registro, estudio y conservación de la red vial inca, iniciándose el Proyecto Qhapaq Ñan - Perú. El proyecto se inició con el desarrollo de las primeras temporadas de reconocimiento para la identificación y registro de la red vial inca. Para este fin se requirió la implementación de equipos de arqueólogos especialistas que realizaron labores de reconocimiento en el ámbito nacional durante los años 2003, 2004 y 2008. Parte de este registro corresponde al presente trabajo en el subtramo Lampas-Choquerecuay, entre las provincias serranas de Bolognesi y Recuay, en el Departamento de Ancash.

La información fue procesada en el año 2014 y, en algunos casos, actualizada mediante la teledetección digital o fotointerpretación arqueológica de imágenes satelitales proporcionada por las plataformas Google Earth y ArcGIS Esri, la que fue luego trasladada a una base de datos SIG, permitiendo la sistematización de la información vectorial (caminos y sitios). Asimismo, la utilización de esta plataforma permitió elaborar propuestas para la identificación de posibles tramos de caminos prehispánicos asociados a sitios arqueológicos, para luego pasar a su verificación de campo mediante el empleo de equipos de posicionamiento satelital GPS, fichas de campo y el registro gráfico. Las imágenes satelitales de alta resolución permitieron la elaboración de la planimetría de los sitios, lo que llevó a la sectorización y determinación de los componentes incas para su posterior verificación en campo.

\section{Sectorización de la vialidad}

Para la sectorización de los tramos del camino prehispánico se utilizó la propuesta metodológica desarrollada por el Proyecto Qhapaq Ñan y presentada en la Guía metodológica para la identificación y registro de Qhapaq Nan (Ministerio de Cultura 2013: 71). La Guía establece cuatro unidades de sectorización con fines de registro y descripción de caminos. Las unidades se clasifican mediante las siguientes categorías: Segmento (0-1 km), Sección (1-10 km), Subtramo (10-100 km) y Tramo $(100+\mathrm{km})$. Esta propuesta de sectorización se ha realizado sobre la base de las distancias registradas entre los sitios arqueológicos vinculados al Qhapaq Ñan. Los segmentos y secciones se han organizado de acuerdo a divisiones arbitrarias mediante su localización en diferentes ámbitos geográficos, como quebradas, lomas, valles y pampas, donde se presentan determinadas características formales y técnicas constructivas, definidas por el relieve y la superficie del terreno y por su estado de conservación (Ministerio de Cultura 2013: 71).

La división en tramo y subtramo responde a la proyección general de un camino arqueológico, que define un itinerario de comunicación entre los diversos asentamientos arqueológicos asociados, como también la ubicación entre localidades actuales que se sobreponen a antiguos centros administrativos y tambos. En el caso del ámbito de estudio, el tramo se circunscribe entre las localidades más importantes en el Callejón de Huaylas, mencionadas en la crónica de Miguel Estete.

\section{IDENTIFICACIÓN Y REGISTRO}

En el subtramo Lampas-Choquerecuay se origina la bifurcación de caminos que se inicia en el centro administrativo inca de Pumpu, ubicado en la meseta de Bombón, en el Departamento de Pasco. El subtramo continúa luego como un ramal del camino longitudinal de la sierra que bordea el flanco occidental de la cordillera Blanca. Se trata de una vía secundaria paralela al camino longitudinal, por las cabeceras de los ríos Huaura, Pativilca y Fortaleza llegando a la meseta de pampa de Lampas. El camino bordea el flanco oriental de la laguna de Conococha, proyectándose hacia el norte hasta Pachacoto, puerta de ingreso al Callejón de Huaylas. 


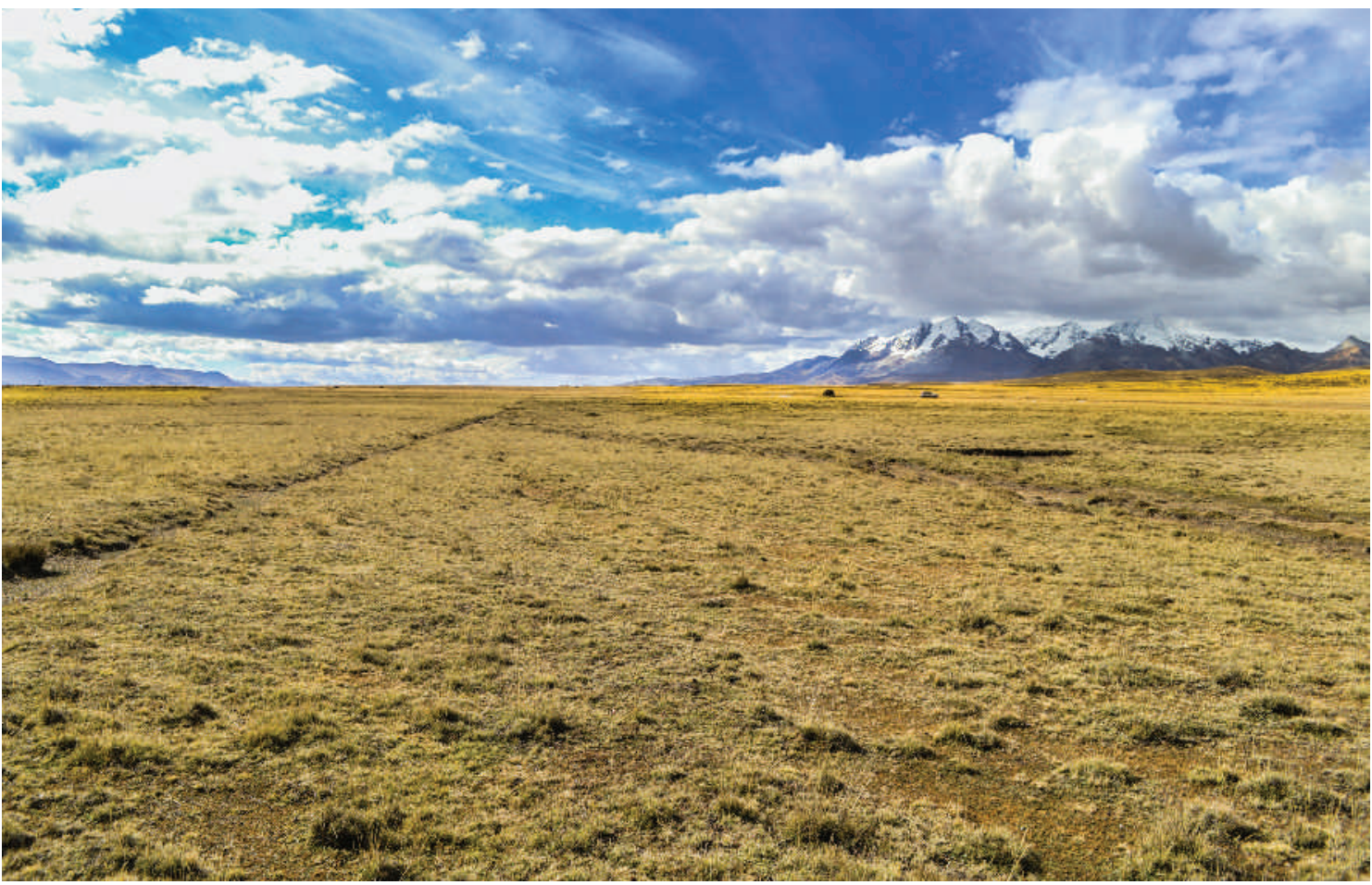

Figura 2. Trazo de camino sobre la pampa de Lampas. Figure 2. Road trace in the pampa de Lampas.

\section{Sección Lampas-Yanamarca $(7,3 \mathrm{~km})$}

El camino se desprende del sitio arqueológico de Lampas ascendiendo a la pampa de Lampas por una suave pendiente, mediante un trazo recto con rumbo sur-norte. En esta sección solo se conserva el trazo del camino, presentándose ligeramente elevado ya que, al parecer, ha perdido parte de su calzada debido a la erosión producida por la humedad del terreno por los extensos bofedales que se han formado por filtraciones de la laguna de Conococha (figs. 2 y 3 ). A $6 \mathrm{~km}$ del sector de Lampas se ubicó una plataforma de planta rectangular de $5 \mathrm{~m} \mathrm{x}$ $3 \mathrm{~m}$, asociada directamente al trazo del camino (fig. 4). Esta sección se asocia al sitio arqueológico denominado Yanamarca o pampa de Lampas Alto (fig. 5), asentamiento constituido por construcciones de plata rectangular y circulares de neta filiación inca.

\section{Subtramo Yanamarca-Huarirraga $(27 \mathrm{~km})$}

El subtramo se proyecta desde la altiplanicie ubicada frente al asentamiento de Yanamarca. El trazo es recto salvo en el corte de la carretera Conococha-Chiquián,aunque es visible en la pampa de Lampas entre los sectores de Mesapampa y Romatambo. El camino se proyecta sobre un terreno ondulado propio del páramo de puna, caracterizado por alineamientos de piedras que delimitan los bordes, cruzando pequeñas quebradas formadas por los riachuelos que nacen de los deshielos de los nevados Jeullarajo y Juchurajo. El camino presenta una calzada de un ancho aproximado de $9 \mathrm{~m}$.

Asociado a este subtramo destaca el sitio arqueológico de Huarirraga, denominado también Huariraka o Inkaraka (Antúnez de Mayolo 2007). Este asentamiento se ubica en una extensa planicie altoandina denominada pampa de Pachacoto, desde la cual se distribuyen dos conjuntos arquitectónicos de patrón ortogonal. El principal presenta estructuras de planta rectangular formando dos canchas y estructuras difíciles de definir por el mal estado de conservación. Destaca un montículo aterrazado el cual presenta dos escalinatas de acceso, las que, por su ubicación y características formales, habrían constituido una plataforma ceremonial o ushnu (figs. 6 y 7). Precisamente, en este sector del sitio confluyen dos caminos, el principal o longitudinal 


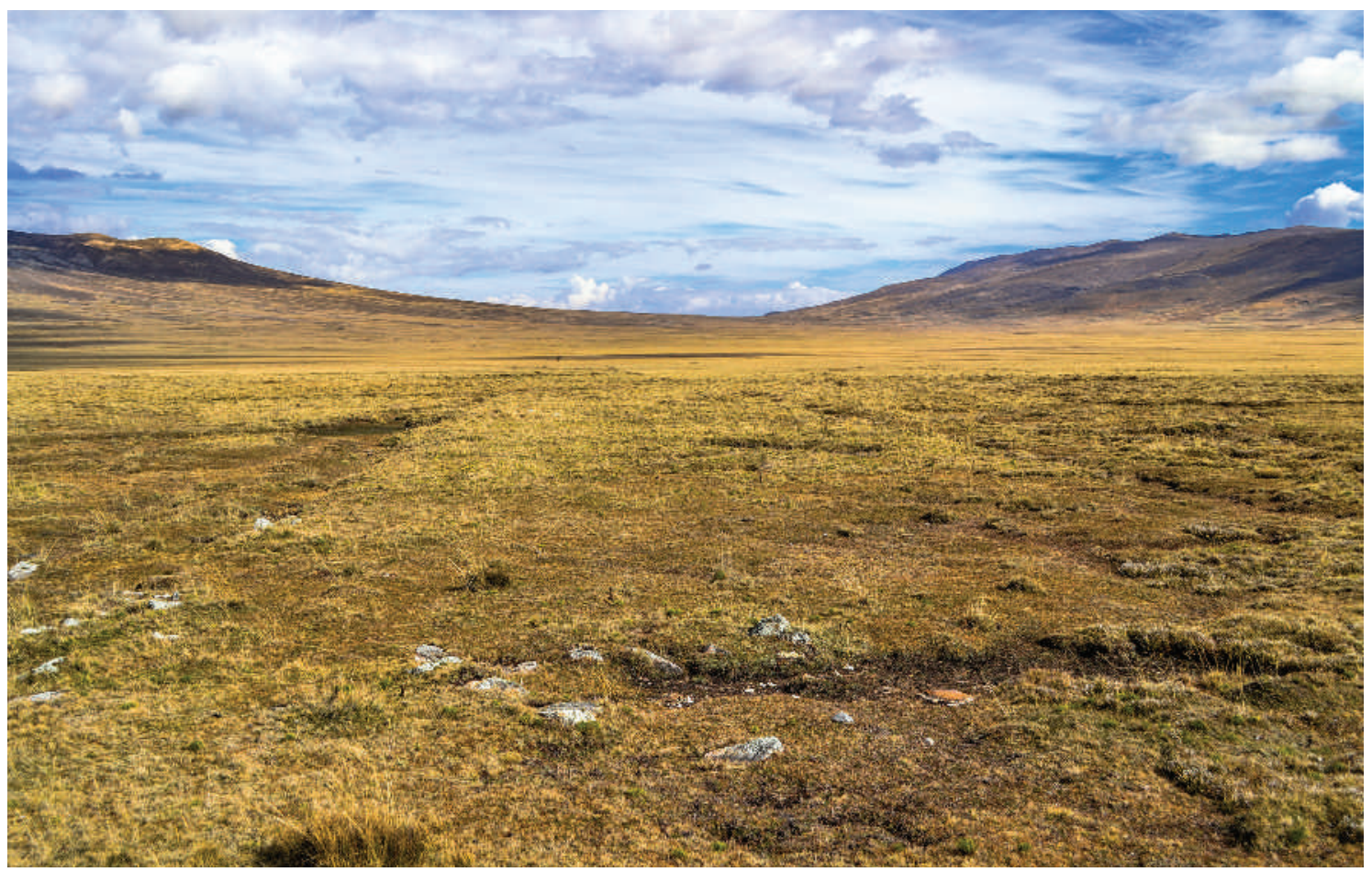

Figura 3. Vista de norte a sur del trazo del camino entre Lampas y Yanamarca. Figure 3. View from the north to the south of the road trace in Lampas and Yanamarca.

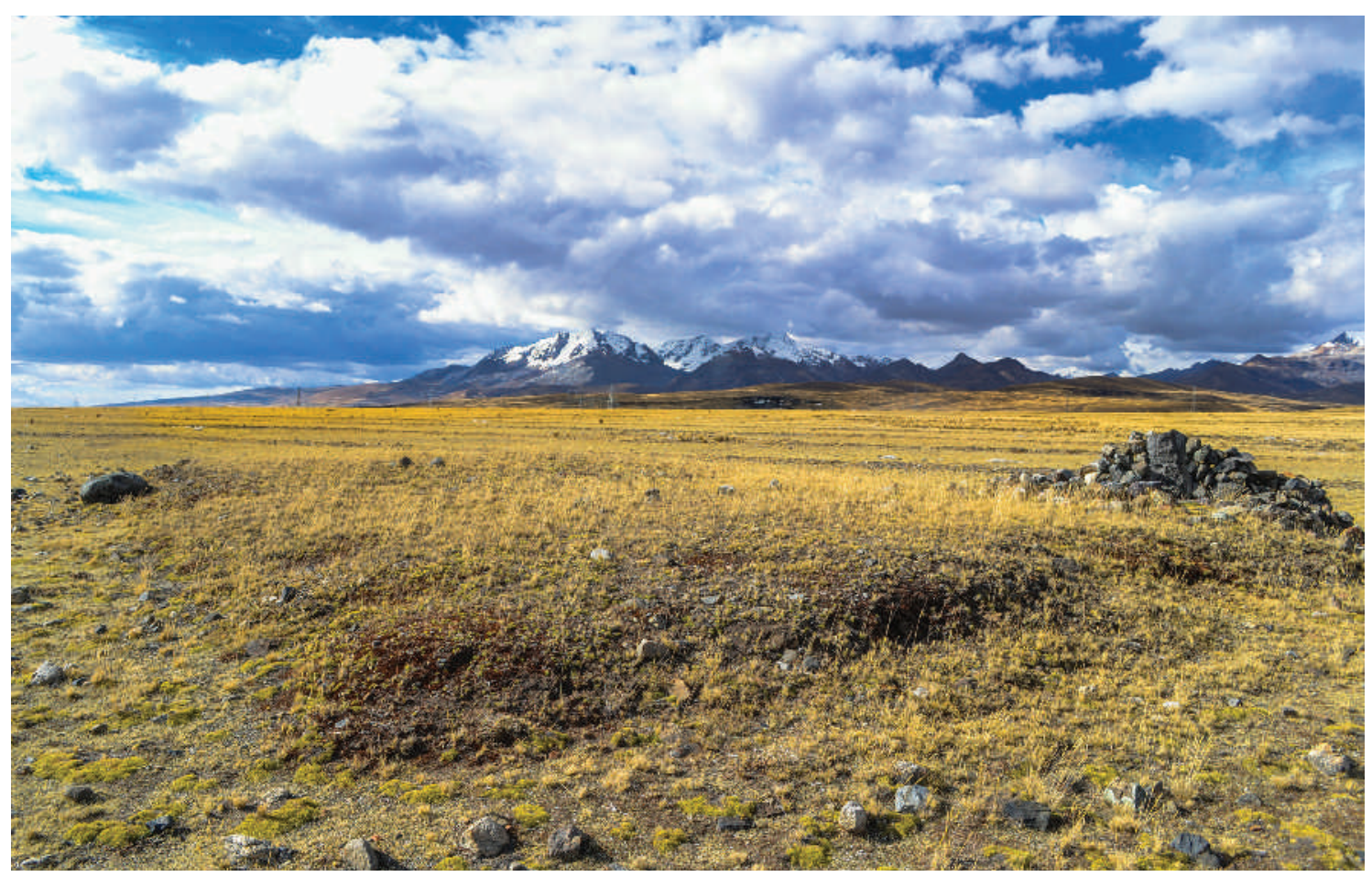

Figura 4. Plataforma ubicada en la vera del camino Yanmarca-Huarirraga. Figure 4. Plataform on the side of the Yanmarca-Huarirraga road. 


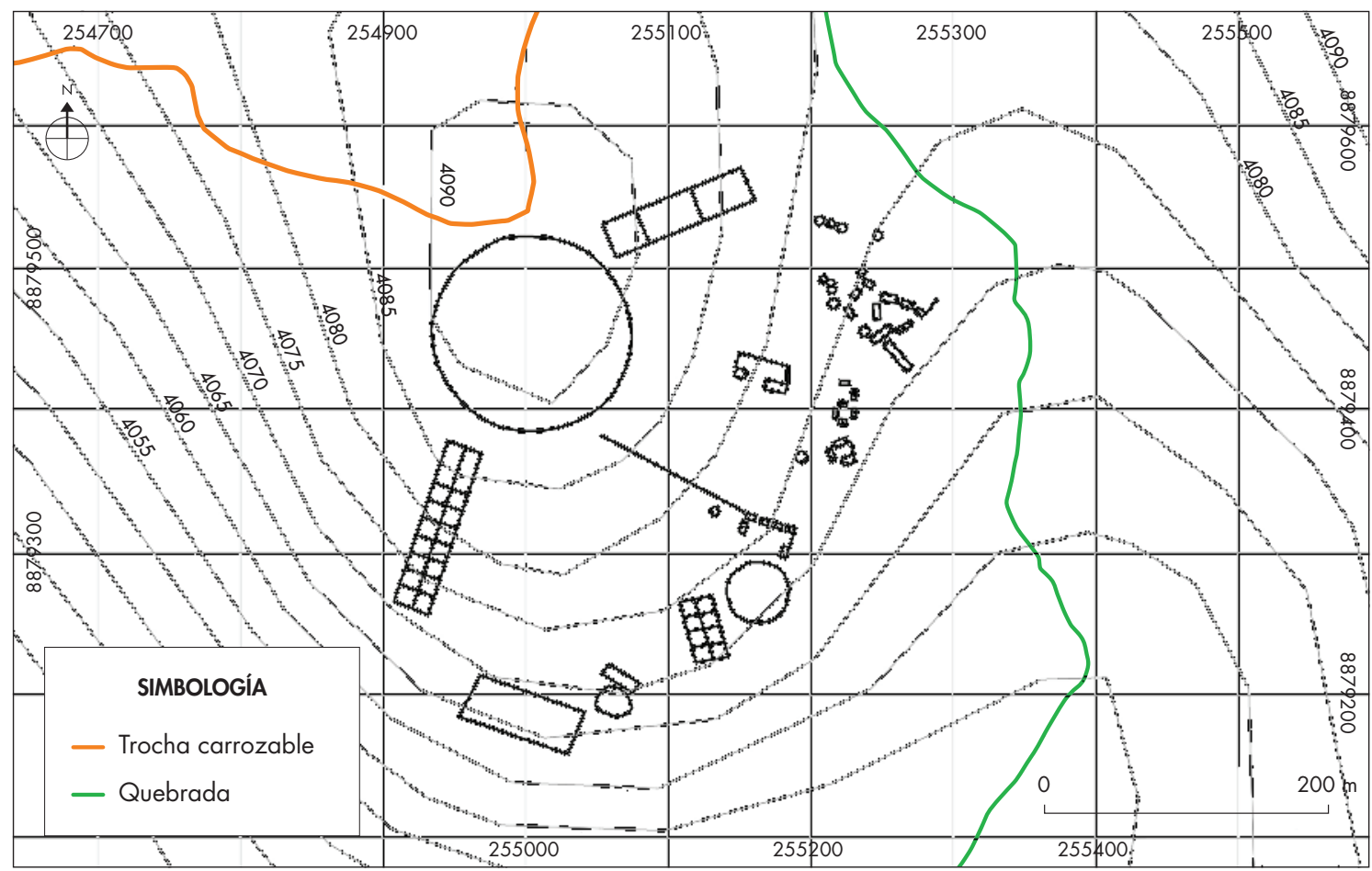

Figura 5. Croquis del sitio de Yanamarca. Figure 5. Yanamarca site diagram.

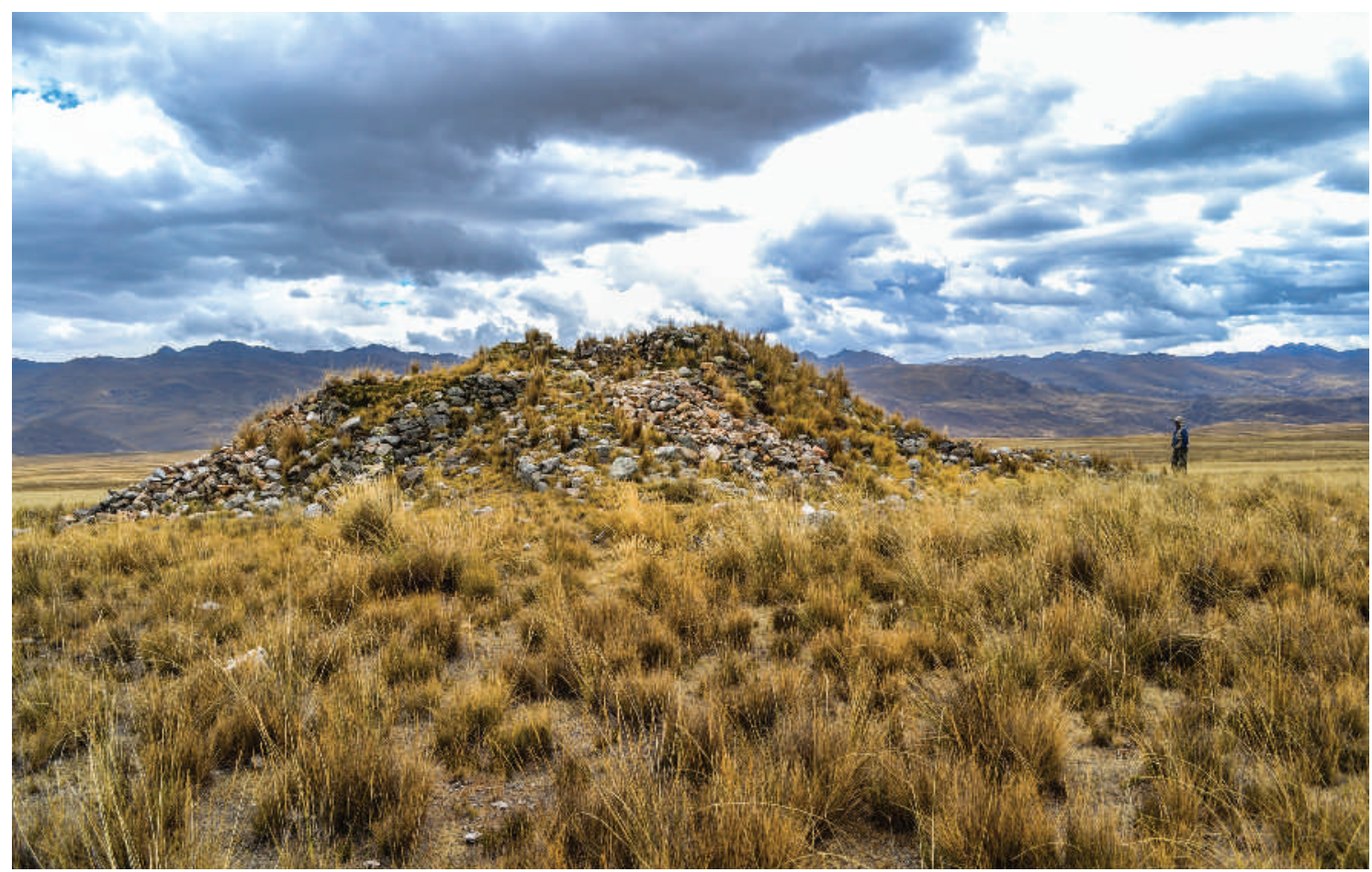

Figura 6. Plataforma ceremonial de Huarirraga. Figure 6. Ceremonial platform of Huarirraga. 
que se orienta de sur-norte y otro secundario que se proyecta de oeste-este hacia la cima del cerro Yeso.

\section{Sección Huarirraga-cerro Yeso (6 km)}

Esta sección comprende un camino formalmente construido de $28 \mathrm{~m}$ de ancho, delimitado por alineamiento de piedras hacia ambos lados. El tramo se orienta desde la plataforma principal de Huarirraga orientándose hacia el sureste y proyectándose a la cima del cerro Yeso (4624 msnm), con una longitud de $6 \mathrm{~km}$. Es posible que este camino se proyecte hacia la cima del nevado Caullarajo o Jeullarajo, denotándose por su orientación como un camino de índole religioso, posiblemente vinculado a capacochas. Esperamos continuar prontamente con los estudios de esta sección para definir su significación (fig. 8).

\section{Sección Huarirraga-Pachacoto $(8,5 \mathrm{~km})$}

Esta sección es una de las mejores conservadas y se presenta como un camino encerrado por muros bajos en ambos costados, formados por dos hileras de piedra, con un ancho de $50 \mathrm{~cm}$. El camino adquiere un ancho promedio de $28 \mathrm{~m}$ (fig. 9) y está formado por una calzada de tierra y piedras sueltas. El trazo del camino se proyecta en un trayecto aproximado de $8,5 \mathrm{~km}$ de longitud desde el asentamiento de Huarirraga hacia el sitio arqueológico de Pachacoto, el que destaca ya que es mencionado en las primeras crónicas soldadescas. El sitio de Pachacoto se encuentra formado por una cancha definida por 4 estructuras de planta rectangular de $5 \mathrm{~m}$ de ancho $\mathrm{x} 18 \mathrm{~m}$ de largo, dispuestas en el entorno de un patio central delimitado por un muro perimétrico (fig. 10). Lamentablemente, este sitio se encuentra en mal estado de conservación debido a factores antrópicos.

\section{Subtramo Pachacoto-Choquerecuay $(16 \mathrm{~km})$}

Este camino continuaba desde Pachacoto hacia el sitio arqueológico de Pueblo Viejo o Choquerecuay, trazo que actualmente ha desaparecido producto del reemplazo de la carretera Catac-Chavín y una trocha carrozable que se proyecta por el antiguo trazo con dirección al sitio de Choquerecuay o Pueblo Viejo, ubicado al costado derecho del río Santa.
En este subtramo se ha registrado el sitio arqueológico de Pueblo Viejo, formado por una plaza de planta trapezoidal cruzada por el camino que ingresa de sur a norte. El sitio incluye dos sectores claramente diferenciables. El sector bajo está formado por la primera plaza, frente a dos estructuras de planta rectangular, posiblemente kallankas; el segundo sector, ubicado en la parte alta, está formado por un muro de contención que divide la primera plaza con la parte más elevada, en la cual se ubica una estructura escalonada, construida sobre un montículo natural; junto a la estructura escalonada se encuentran tres estructuras de planta cuadrangular que semejan tres canchas (figs. 11 y 12).

Por su ubicación entre los límites de la región quechua e inicio de la región suni, el área debió producir abundantes tubérculos como la papa, por lo que destaca en el sitio un sector de depósitos o qolqas ubicadas en una colina hacia el este del sitio. Este componente arquitectónico es un patrón recurrente en los grandes centros administrativos incas y permitía el acopio de la producción provincial estatal y el control de la producción de los grupos locales asentados en la cuenca alta del Santa.

\section{Otros ramales (fig.13)}

Se han registrado caminos transversales que se bifurcan del camino principal hacia ambas márgenes de la cordillera Blanca y Negra. Del asentamiento de Lampas se bifurcan dos caminos. El primero hacia el valle bajo del Pativilca, cortando parte del macizo geológico de la formación Fortaleza. En su extremo sur, este camino desciende hacia la antigua provincia de Ocros y continúa hacia el valle bajo. El segundo ramal está orientando hacia el este y conduce hacia las cabeceras de la cuenca alta del Pativilca, conectándose con otro ramal de la ruta al Huayhuash.

Del sitio arqueológio de Pachacoto se desprenden varios caminos, destacando históricamente el camino que conectaba con el valle de Fortaleza por la vía prehispánica hacia Marca. La ubicación del sitio es estratégica, ya que permitió la articulación con otras regiones.

El asentamiento inca de Pueblo Viejo permite enlazar con los valles de Huarmey y Casma, por un camino que baja por las estribaciones occidentales de la cordillera Negra, hacia Huarmey por el paso Huancapeti, entre Aija y Recuay, y hacia Casma por el paso de Puntacallan. Otro camino se orienta de Olleros rumbo 


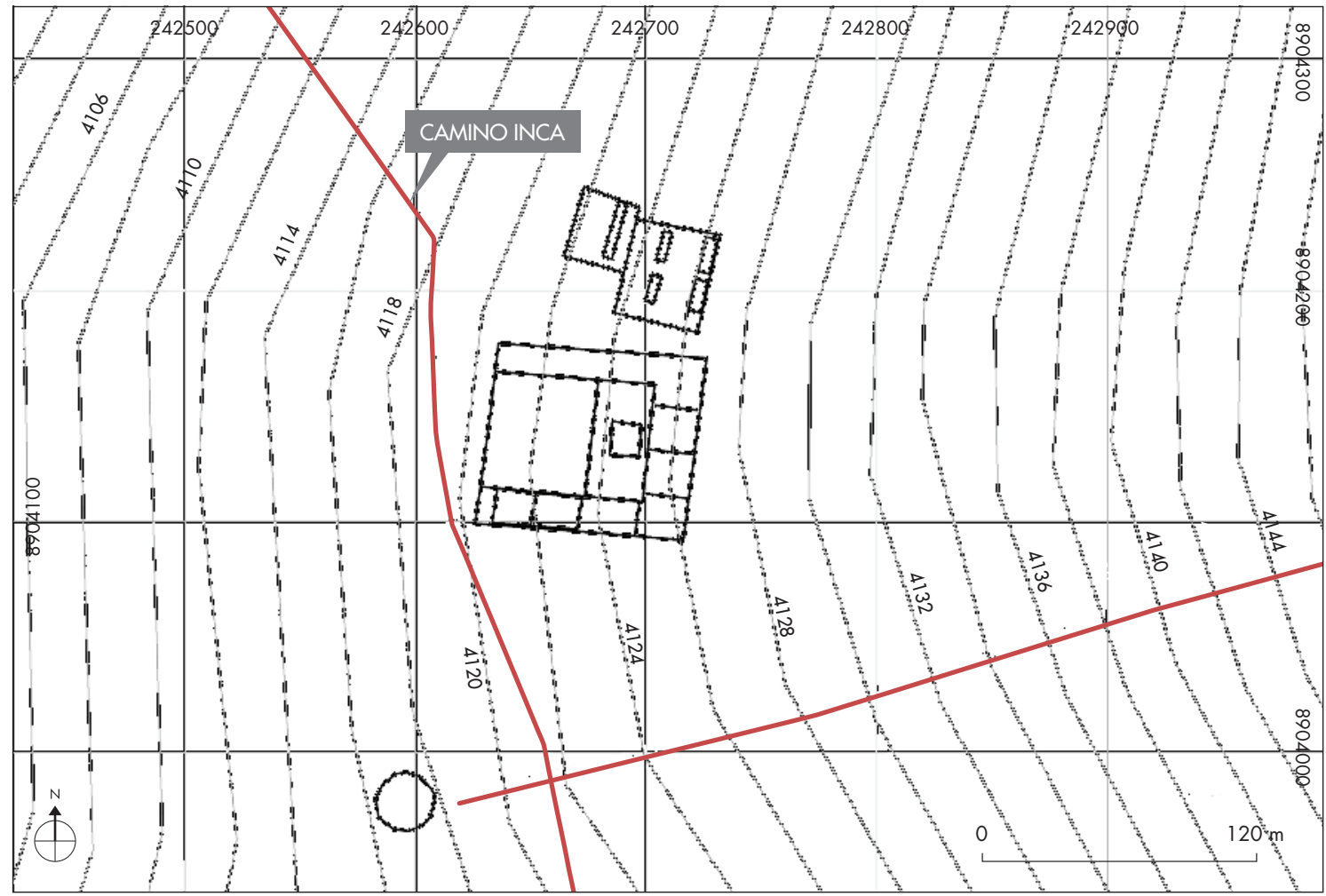

Figura 7. Planimetría del sitio de Huarirraga. Figure 7. Huarirraga site planimetric sketch.

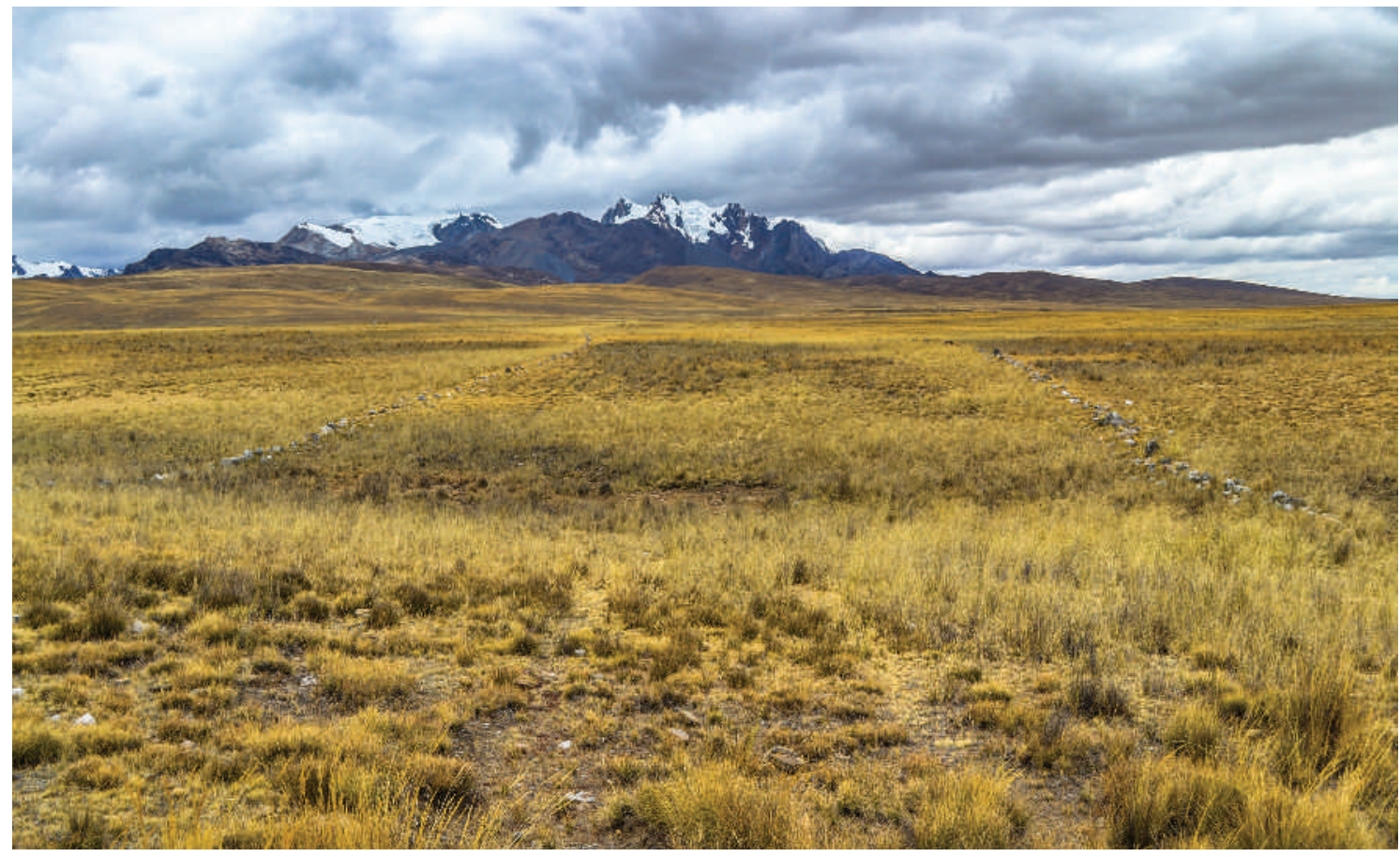

Figura 8. Trazo del Camino Inca entre Huarirraga-Cerro Yeso. Figure 8. Trace of the Inka Road between Huarirraga and Cerro Yeso. 


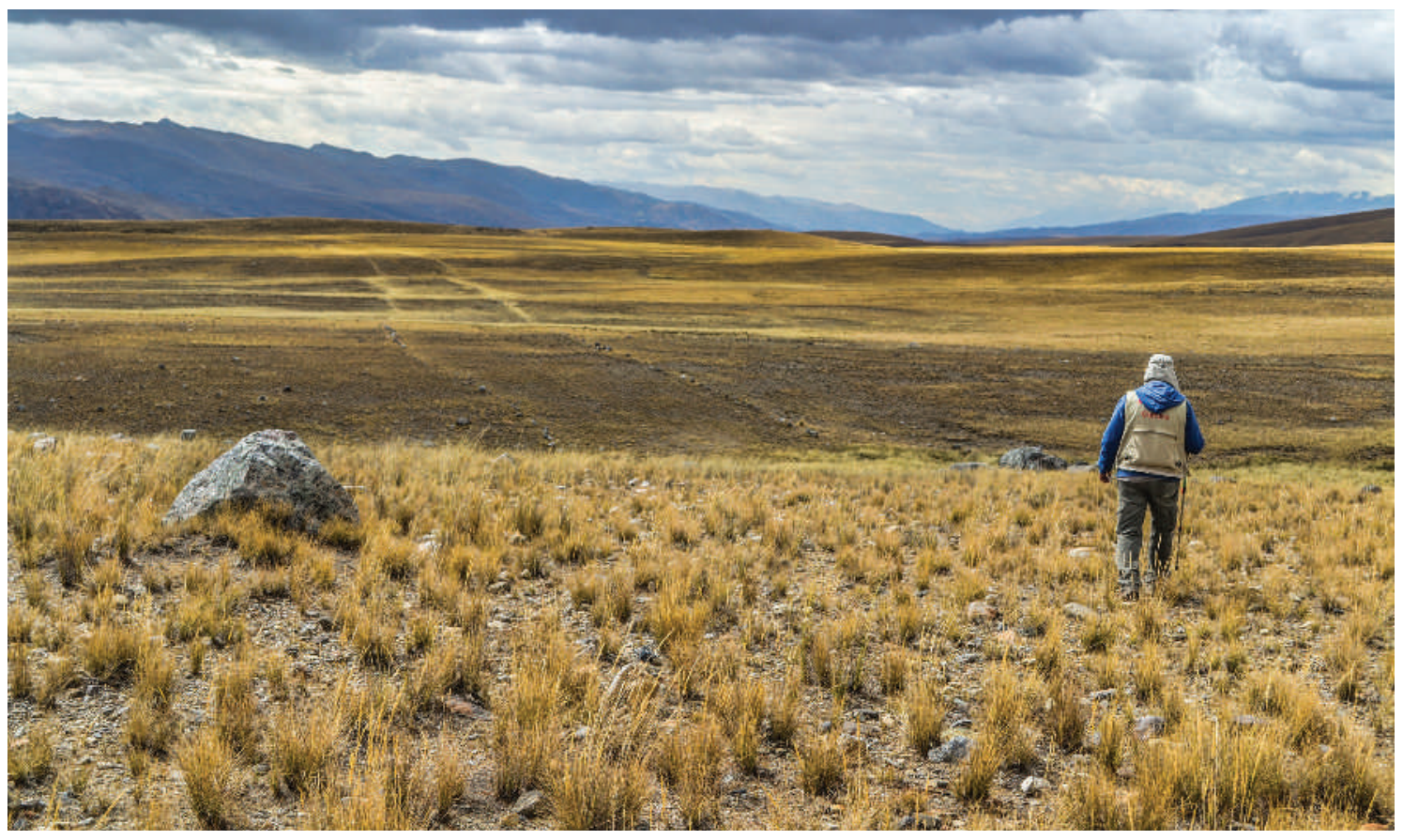

Figura 9. Trazo del Camino Inca entre Huarirraga-Pachacoto. Figure 9. Trace of the Inka Road between Huarirraga-Pachacoto.

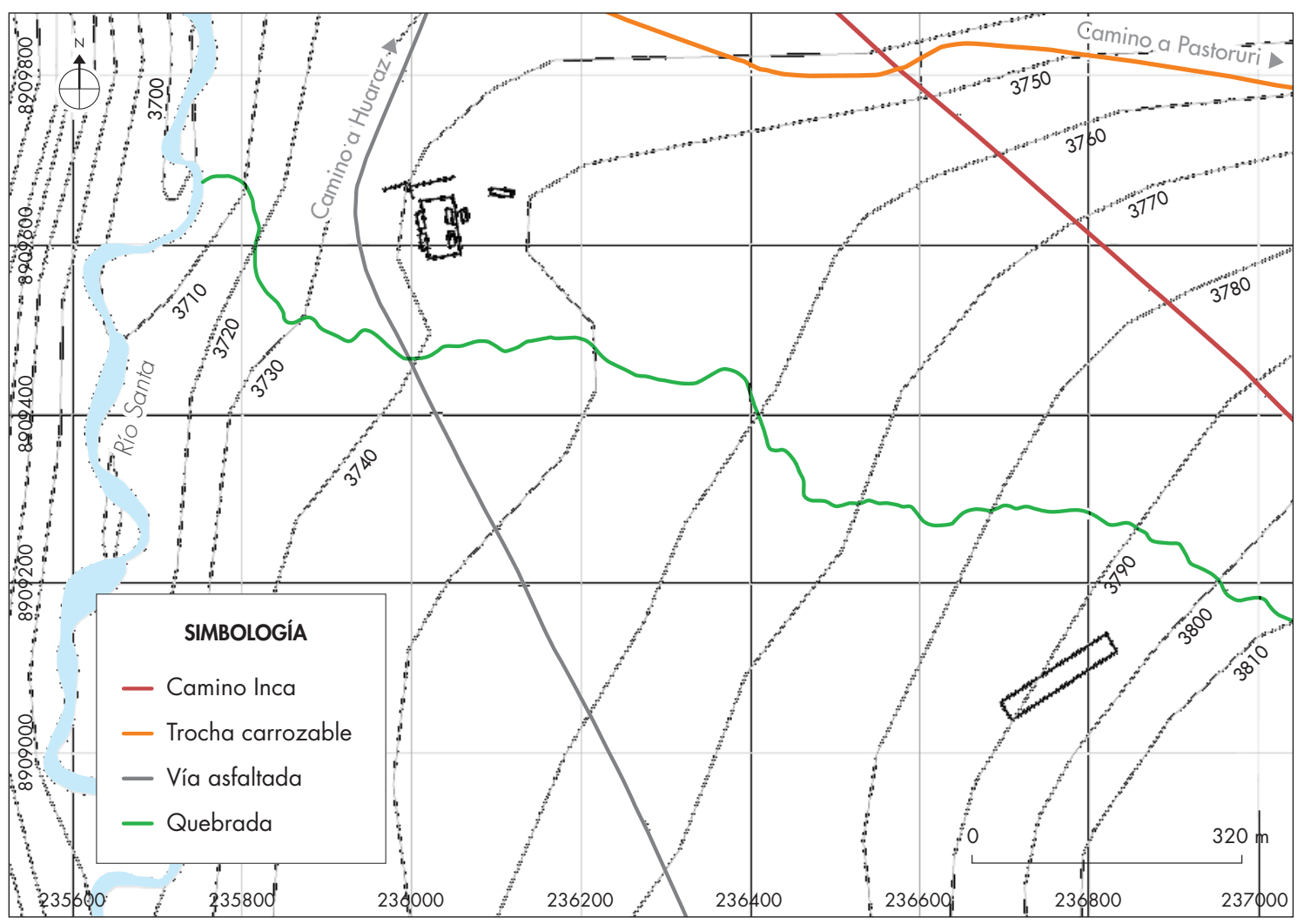

Figura 10. Croquis del sitio de Pachacoto. Figure 10. Pachacoto site diagram. 


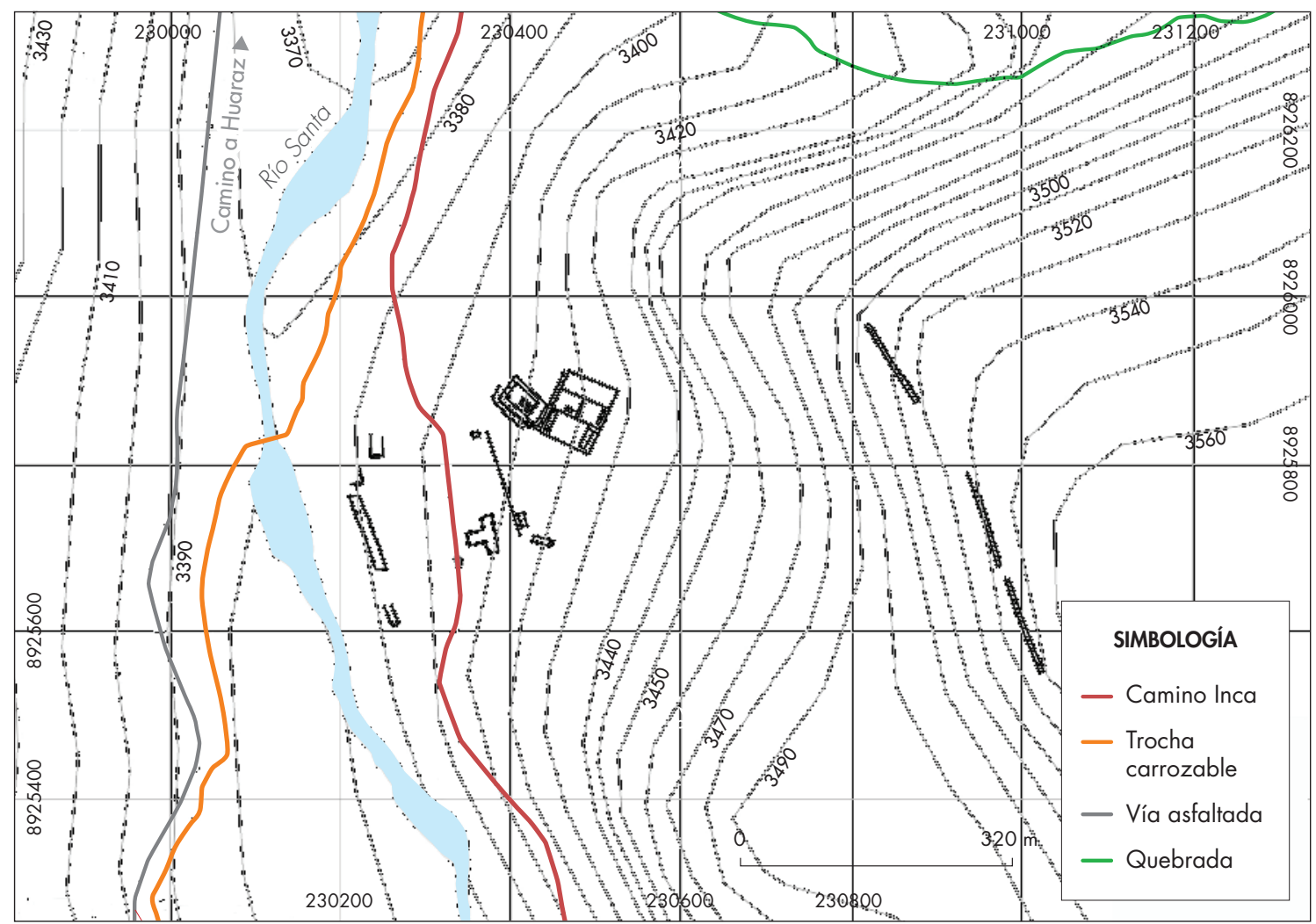

Figura 11. Croquis del sitio de Pueblo Viejo o Choquerecuay. Figure 11. Diagram of the Pueblo Viejo or Choquerecuay site.

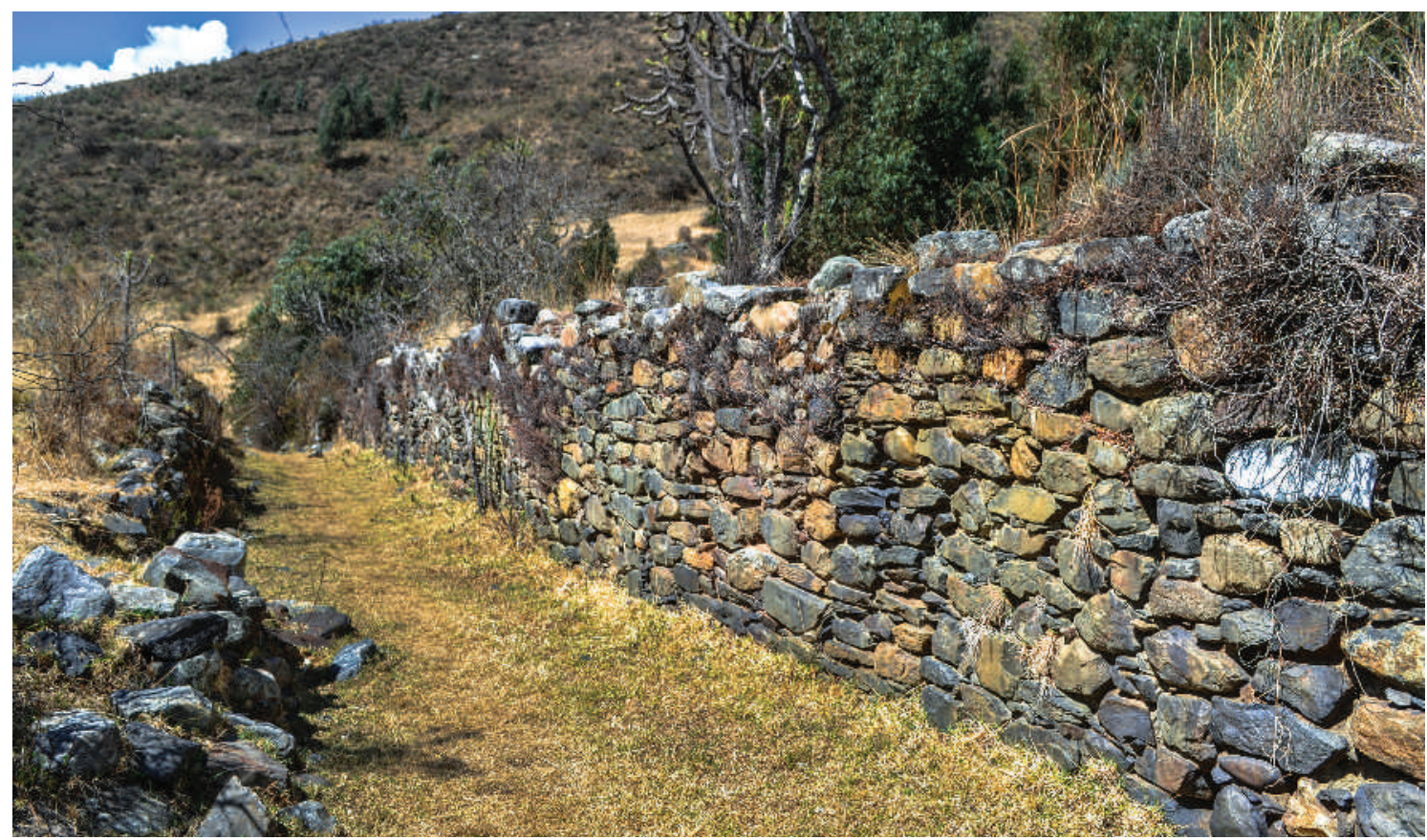

Figura 12. Sector de las kanchas en Choquerecuay. Figure 12. Area of the kanchas in Choquerecuay. 


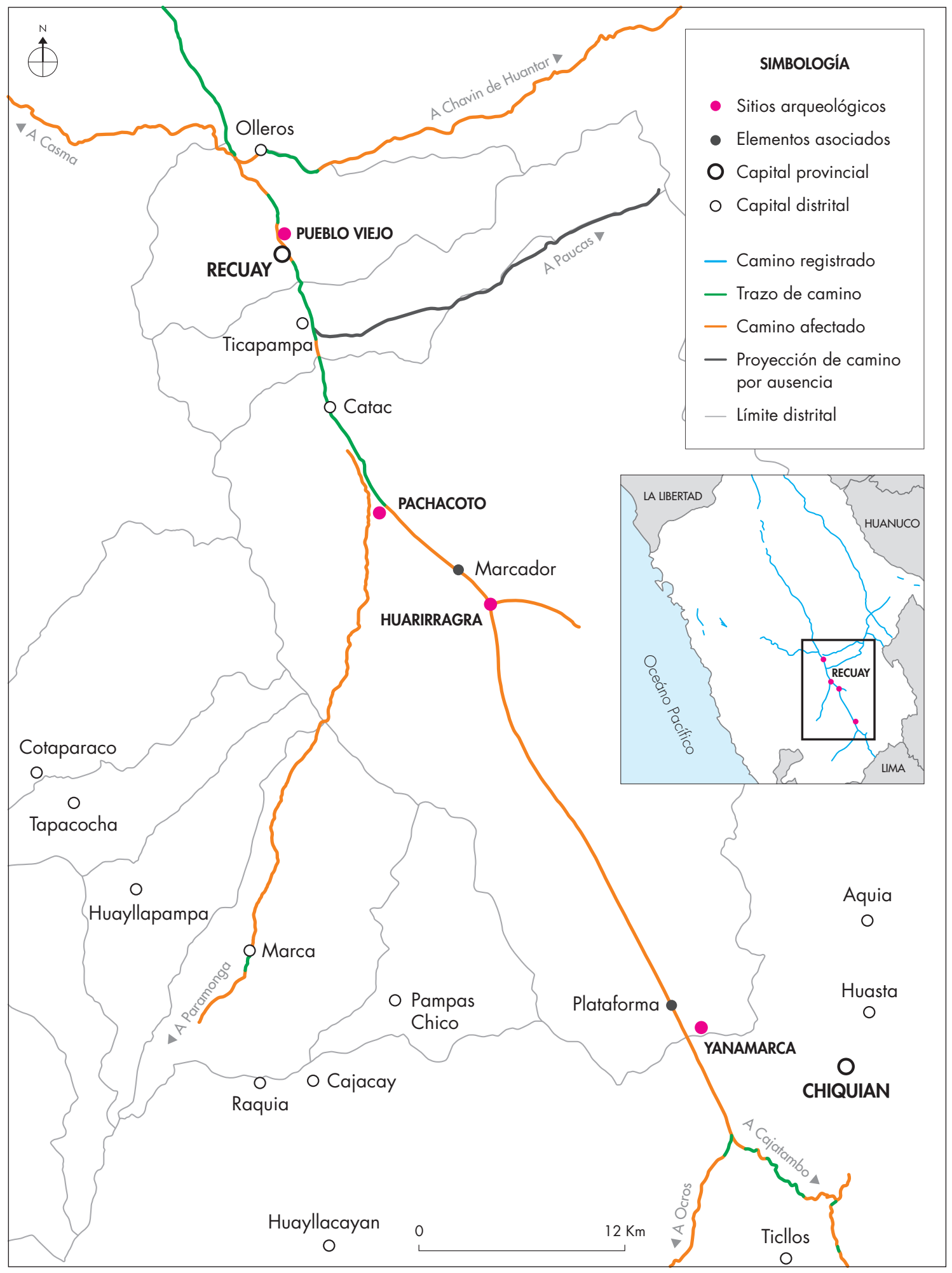

Figura 13. Mapa del registro de la red vial en Lampas - Choquerecuay. Figure 13. Map of the roads documented in the Lampas - Choquerecuay area. 
al portachuelo de Yanashallash, bajando hacia el valle de Pushca por el centro ceremonial de Chavín de Huantar, continuando por su rivera hasta el puente prehispánico de Chocchian (Llamellín) y cruzando el Marañón, una ruta de interconexión con el oriente y la ceja de selva que lleva al valle del Monzón.

\section{DISCUSIÓN}

A lo largo del sistema vial se han registrado ramales de caminos que el Estado Inca construyó para unir áreas de suma importancia por su potencial económico y su carácter simbólico. Así tenemos ramales que se deprenden de los principales asentamientos para unirse después de varios kilómetros, en otro punto de importancia. Por ejemplo, el camino al Collasuyu que bordeaba ambos flancos del lago Titicaca, ${ }^{4}$ bifurcándose en la actual localidad de Pucara, y uniéndose en el extremo sur del lago en el sector denominado como Laja (actual Bolivia).

Recientes estudios en la meseta de Bombón han permitido comprobar que el camino longitudinal se bifurcaba en el sitio de Chacamarca para continuar por la margen oriental del lago Chinchaycocha, asociado a asentamientos de filiación Intermedio Tardío (Guido Casaverde y Alfredo Bar, comunicación personal).

El subtramo Lampas-Choquerecuay sería parte de un ramal del camino longitudinal de la sierra que se bifurcaba en el centro administrativo de Pumpu, continuando por el flanco occidental de la cordilleras de Chacua, Raura, Huayhuash y la cordillera Blanca, cruzando valles interandinos de suma importancia económica, política y religiosa para el Estado Inca. El concepto geográfico y paisajístico está integrado en la planificación del territorio por los Incas, quienes controlaban grandes zonas de pastoreo y producción de camélidos, en especial la llama (Lama glama), único animal utilizado para el transporte de carga en el Tawantinsuyu. El carácter ceremonial de la vialidad inca se observa por la ubicación del asentamiento de Huarirraga, al pie de la cadena montañosa donde destaca el nevado Jeullarajo o Caullarajo. Allí se proyecta un camino de $29 \mathrm{~m}$ de ancho desde la plataforma principal con una longitud aproximada de $6 \mathrm{~km}$, orientándose hacia el este con dirección a la cima del cerro Yeso. Dicho camino continuaba posiblemente en ascenso hacia la Cordillera (Vitry 2007).
Algunos indicadores, como la asociación de sitios, permiten plantear el carácter económico y religioso. Por ejemplo, la construcción de Choquerecuay como un centro administrativo que constituyó "cabeza de provincia" en la parte sur de la Provincia inca de Huaylas, parcialidad que tomó el nombre de Rurinhuaylas. Por otro lado, queda por resolver el rol que jugó el asentamiento de Pumacallan con respecto a la parte sur de la Provincia de Huaylas. Este asentamiento se encuentra ubicado en el centro de la actual ciudad de Huaraz, donde se han hallado evidencias de ocupación inca (Serna 2009).

El sitio arqueológico de Choquerecuay o Pueblo Viejo comprende una extensión aproximada de 44 ha, conservando componentes arquitectónicos de filiación inca, como la estructura escalonada que destaca por su volumen y posible funcionalidad como ceremonial. Esta estructura presenta 3 plataformas superpuestas y una escalinata orientada al noreste, permitiendo el acceso a la parte superior, donde se ubica un recinto de planta rectangular. Su ubicación estratégica le permite, además, tener una visión panorámica de todo el conjunto y del camino que cruza la plaza dividiendo al sitio en dos mitades. Consideramos esta estructura como una plataformas ceremonial ushnu. Como veremos, se han localizado a lo largo del sistema vial establecimientos incas con ushnus conformados como plataformas superpuestas, por ejemplo: en Huánuco Pampa (presenta 3 plataformas superpuestas), Vilcahuaman (4 plataformas), Curamba (3 plataformas), Pumpu (3 plataformas) (Monteverde 2010: 49).

El sitio de Pachacoto es importante por su alto grado de conectividad, ya que se asocia al camino longitudinal que se proyecta por la margen derecha del río Santa. Se articula con una red de caminos transversales, tanto para el occidente como para el oriente, conectando con establecimientos de la costa y con regiones de alta productividad como los valles de Pushca y el Vizcarra, rutas que permitían el acceso a la cuenca alta del Marañón. Hacia el sur se conecta con la pampa de Pachacoto y Lampas, áreas de alta producción de camélidos y recursos hídricos. Así, la red vial inca permitía el control y administración del flujo de bienes de producción que circulaban hacia los principales centros administrativos como Huánuco Pampa.

Los sistemas de depósitos asociados a los centros administrativos, explicados por algunos autores y registrados en Huánuco Pampa, Pumpu, Xauxa, destacan 
como una característica en los componentes incas. Los 5 asentamientos registrados en Choquerecuay y Pachacoto cuentan con qolqas o depósitos claramente identificados, como en Choquerecuay, caracterizado por estructuras alargadas que presentan subdivisiones internas que forman pequeñas estructuras de planta rectangular. En Pachacoto se han registrado aproximadamente 20 estructuras de planta circular alineada y orientada hacia el noreste. En Huarirraga y Lampas no se han ubicado sectores diferenciados que nos puedan indicar construcciones que cumplieron la función de qolqas. En Yanamarca, el sector 1 corresponde a un conjunto de estructuras circulares que falta definir, pero es posible que conformen áreas de depósitos.

Los sitios de Huarirraga y Yanamarca cumplieron funciones productivas para la crianza de grandes hatos de camélidos, ya que se asocian a una gran estepa de puna con abundante pastizales, lagunas y bofedales aptos para la crianza selectiva de llamas y alpacas, permitiendo que esta actividad económica fuera muy productiva. Un indicador arqueológico que nos permite confirmar esta afirmación es el conjunto de estructuras de planta cuadrangular y rectangular que hasta el día de hoy son reutilizadas por los pastores de puna como corrales. Asimismo, en Yanamarca destacan dos estructuras de gran extensión de planta circular que no son propias de otros asentamientos incas al menos no se ha reportado en tambos o centros administrativos, probablemente reutilizados o de origen colonial no se descarta su origen prehispánico. También el registro de dos estructuras ortogonales fueron utilizadas como depósitos o como campos de cultivo (Casaverde \& López 2013).

Huarirraga, sitio de índole ceremonial de 30 ha, destaca por una plataforma ceremonial o ushnu de la cual se desprenden tres caminos principales que articulan con Choquerecuay y Yanamarca. Una tercera ruta se desprende con orientación este hacia el cerro Yeso, continuando a la cima del nevado Caullarajo. Creemos que se trata de uno de los principales santuarios de altura venerado por los incas en esta región y por el cual esta región de Lampas y Huaylas se convirtió en una de las principales receptoras de Capacochas, enviados a diferentes confines del Tahuantinsuyo (Hernández Príncipe 1923 [1621]). Precisamente la documentación histórica relata que el curaca de Ocros envió a su hija Tanta Carhua quien, luego de regreso del Cusco, fue ofrendada y colocada en un santuario ubicado en un paraje denominado como "Aija".

\section{CONCLUSIONES}

El subtramo Lampas-Pueblo Viejo presenta una conectividad valiosa que se articulaba mediante un camino longitudinal de norte a sur, con características formales. El camino, con un ancho de promedio de $28 \mathrm{~m}$, permitió el transito fluido de las comitivas estatales. Los incas fundaron asentamientos sobre su eje longitudinal, los cuales funcionaron como centros administrativos, ceremoniales y tambos, desempeñando un rol activo y dinámico y permitiendo el desarrollo de toda la red caminera en esta región.

La vialidad inca cumplió funciones de interacción social, política y económica, lo que permitió al Estado Inca controlar diferentes espacios geopolíticos con un alto grado de significación simbólica, como lo fue, por ejemplo, la vía de carácter ceremonial que se proyectaba desde del sitio de Huarirraga a la cima del nevado Caullarajo o Jeullarajo (tablas 1 y 2 ).

Finalmente, consideramos que el presente texto es una aproximación al estudio de la red vial inca en el extremo sur de la Provincia inca de Huaylas y es necesario abordar la problemática histórico-arqueológica mediante la metodología de registro de información que el Proyecto Qhapaq Ñan Perú viene trabajando con ayuda de la guía básica para la identificación y registro del sistema vial inca. También es necesario implementar trabajos arqueológicos sistemáticos que incluyan intervenciones puntuales en el camino y en los sitios asociados para abordar temas como el paisaje cultural, estrategias de conquista, movimiento y dinámicas sociales en relación al camino prehispánico.

\section{NOTAS}

${ }^{1}$ Las mitades hurin y hanan estaban subdivididas cada una en seis guarangas (idealmente 6.000 tributarios cada una). Así, tenemos que la parcialidad Huringuaylas estaba divididas en las guarangas de Marca, Allaucapomas, Ichopomas, Ichochonta, Allaucaguaraz y Ichocguaraz. La parcialidad Hananguaylas estaba dividida en las guarangas de Huaylas, Tocas, Guambo, Mato, Icas y Rupas (Zuloaga 2011: 69).

${ }^{2}$ El establecimiento de Hatun Huaylas debió estar asentado en el área que corresponde al actual poblado de Huaylas, en especial el área donde se encuentra la iglesia matriz de origen colonial, construida sobre una terraza artificial a la que se accede por una escalinata desde la plaza de armas de la localidad, en su lado oeste. Esta afirmación tendría 
Tabla 1. Red de caminos en el subtramo Lampas - Choquerecuay. Table 1. Road network in the subsection LampasChoquerecuay.

\begin{tabular}{|c|c|c|c|c|}
\hline $\begin{array}{c}\text { CAMINOS } \\
\text { PREHISPÁNICOS }\end{array}$ & SECTORIZACION & $\begin{array}{l}\text { LONGITUD } \\
\text { (KM) }\end{array}$ & $\begin{array}{l}\text { ANCHO } \\
\text { (M) }\end{array}$ & TIPO \\
\hline Lampas - Pueblo Viejo & Subtramo & 62 & 25 & Longitudinal \\
\hline Lampas - Ocros & Subtramo & 35 & 2 & Transversal \\
\hline Lampas - Chiquian & Sección & 9 & 1 & Secundario \\
\hline Huarirraga - Cerro Yeso & Sección & 6 & 20 & Ceremonial \\
\hline Pachacoto - Valle de Fortaleza & Subtramo & 37 & 2 & Transversal \\
\hline Olleros - Chavín de Huantar & Subtramo & 35 & 2 & Transversal \\
\hline Pueblo Viejo - Huarmey & Tramo & 103 & 1 & Transversal \\
\hline Pueblo Viejo - Casma & Tramo & 95 & 2 & Transversal \\
\hline
\end{tabular}

Tabla 2. Sitios asociados al subtramo Lampas - Choquerecuay. Table 2. Sites related to the subsection LampasChoquerecuay.

\begin{tabular}{|c|c|c|c|c|}
\hline $\begin{array}{l}\text { SITIOS } \\
\text { PREHISPÁNICOS }\end{array}$ & ALTITUD & $\begin{array}{c}\text { COMPONENTES } \\
\text { ARQUITECTONICOS }\end{array}$ & $\begin{array}{l}\text { AREA } \\
(\mathrm{Ha})\end{array}$ & FUNCIONALIDAD \\
\hline Lampas & 4030 & $\begin{array}{c}\text { Canchas, estructuras circulares, } \\
\text { estructuras rectangulares }\end{array}$ & 11 & Tambo (residencial) \\
\hline Yanamarca & 4097 & $\begin{array}{c}\text { Canchas, kallancas, plaza, corrales, } \\
\text { plataforma (ushnu?) }\end{array}$ & 17 & $\begin{array}{l}\text { Tambo (residencial, } \\
\text { productivo, ceremonial) }\end{array}$ \\
\hline Huarirraga & 4131 & $\begin{array}{l}\text { Canchas, corrales, plataforma } \\
\text { (ushnu), kallancas }\end{array}$ & 48 & $\begin{array}{l}\text { Tambo (residencial, cere- } \\
\text { monial, productivo) }\end{array}$ \\
\hline Pachacoto & 3750 & Cancha, corrales & 2 & $\begin{array}{l}\text { Tambo (residencial, } \\
\text { control) }\end{array}$ \\
\hline $\begin{array}{l}\text { Pueblo Viejo o } \\
\text { Choquerecuay }\end{array}$ & 3421 & $\begin{array}{l}\text { Plaza, kallancas, canchas, collqas, } \\
\text { plataforma escalonada (ushnu?) }\end{array}$ & 54 & Centro administrativo \\
\hline
\end{tabular}


que ser corroborada con trabajos sistemáticos de investigación arqueológica, incluyendo excavaciones que permitan determinar el carácter ocupacional de la iglesia matriz. Es importante anotar que, en las inmediaciones de Huaylas, se ha registrado el sitio de Chupacoto, asentamiento formativo compuesto por varias plataformas superpuestas (Chupagrande), ubicándose en superficie fragmentos de cerámica de estilo Huaraz y Recuay. Estas evidencias indican, efectivamente una continua secuencia ocupacional desde el Formativo hasta la época Colonial.

${ }^{3}$ La primera fuente histórica fue escrita por Miguel de Estete (1534), quien acompaña a Hernando Pizarro como veedor. En dicho documento se señala que los españoles tomaron el camino que bajaba desde Pachacoto a la costa por el valle de Marca y Fortaleza hasta el asentamiento de Paramonga, donde continuaba por el camino de los llanos hasta el santuario de Pachacamac.

${ }^{4}$ El camino que se orienta por el flanco occidental era denominado Urcosuyu y el del flanco oriental Umasuyu (Hyslop 2014).

RECONOCIMIENTOS a mi compañero Julio Fernández por el apoyo en la elaboración de la planimetría y mapas del presente texto. Asimismo, a Guido Casaverde, Alfredo Bar y Miguel Cabrera por las sugerencias y comentarios que permitieron enriquecer el presente trabajo. Finalmente a Sonia Ríos por la revisión del presente texto.

\section{REFERENCIAS}

AlCALDE, A., 2003. Exploración arqueológica en la cuenca alta del río Santa. En Arqueología de la sierra de Ancash. Propuestas y perspectivas, B. Ibarra, Ed., pp. 371-404. Lima: Instituto Cultural RvNA.

Antúnez de Mayolo, S., 2007. Vida y obra. El telúrico, el indigenista, el científico y tecnólogo. Lima: IBEGRAF.

Bueno, C., 1951. Geografía del Perú virreinal, siglo XVIII. Lima: Azángaro.

Casaverde, G., 2013. Período de transición colonial vs. Inca: el caso de la sierra de Lima. Cuadernos del Qhapaq Nan 1 (1): 58-91.

Casaverde, G. \& S. López, 2008. Principios metodológicos para la identificación y registro arqueológico de los Caminos Inka. Inka Llaqta: Revista de Investigaciones Arqueológicas y Etnohistóricas Inka 1: 79-101.

Casaverde, G. \& S. López, 2013. Estructuras ortogonales en el Tawantinsuyu. Cuadernos del Qhapaq Ñan 1 (1): 92-115.

Del Busto, J., 2001. Pizarro. Tomo II. Lima: Ediciones cope.

DíAz, A., 2012. Evaluación de la eutrofización de la laguna de Conococha-Ancash. Tesis para optar al título de Ingeniero Ambiental, Facultad de Ciencias del Ambiente, Universidad Nacional Santiago Antúnez de Mayolo,. Huaraz.
Duviols, P., 1973. Huari y Llacuaz: agricultores y pastores: un dualismo prehispánico de oposición y complementariedad. Revista del Museo Nacional 39: 153-191.

EsPINOzA, W., 1981. Un testimonio sobre los ídolos, huacas y dioses de Lampa y Cajatambo. Siglos XV-XVII. Supervivencias en Cajarmaca. Scientia et Praxis (separata) 15: 115-152.

Estete, M., 1929 [1534]. Viaje de Hernando Pizarro desde Caxamalca hasta Jauja. En Verdadera relación de la conquista del Perú, A. Rodríguez-Moñino, Ed. Badajoz: Arqueros.

Hernández, R., 1923 [1621]. Idolatría del pueblo de Ocros. Cabeza desta comunidad. Año de 1621. Revista Inca I: 50-60.

Holdridge, L., 1967. Life zone ecology. San José: Tropical Science Center.

Hyslop, J., 1992. Qhapaq Ñan. El sistema vial incaico. Lima: Instituto Andino de Estudios Arqueológicos- Petróleos del Perú.

Hyslop, J., 2014. Qhapaq Ñan. El sistema vial inkaiko. Lima: Ediciones COPE.

Garcilaso de la Vega, I., 1985 [1609]. Comentarios reales de los Incas. Lima: Ediciones del Centenario del Banco de Crédito del Perú.

LANE, K., 2010. Continuidad y cambio en comunidades Huaylas durante el Período Intermedio Tardío, Inka y Colonial 1000-1615 D.C. Inka Llaqta 1: 7-28.

Pereyra, H., 1989. Chiquian y la Región de Lampas entre los siglos XVI y XVII. Una hipótesis sobre el origen de las campañas de extirpación de idolatrías en el Arzobispado de Lima. Boletín del Instituto Riva Agüero 16: 21-54.

Masferrer, E., 1984. Criterios de organización andina: Recuay siglo Xvir. Boletín del Instituto Francés de Estudios Andinos XIII (1-2): 47-61.

Ministerio de Cultura, 2013. Guía de identificación y registro del Qhapaq Ñan. Lima: Ministerio de Cultura.

Monteverde, L., 2010. La configuración arquitectónica de los ushnus como espacios de libaciones y ofrendas líquidas durante el Tahuantinsuyo. Boletín del Instituto Francés de Estudios Andinos 40 (1): 31-40.

Pino, J., 2004. El ushnu inka y la organización del espacio en los principales tampus de los wamani de la sierra central del Chinchaysuyu. Chungara 36 (2): 3003-3011.

Pulgar, J., 1967. Geografía del Perú: las ocho regiones naturales. Lima: Ausonia.

Robles, R., 2003. Las iglesias andinas: huellas de la cristianización y la religiosidad popular. Revista de Antropología 3 (3): 103-162.

Rostworowski, M., 2008. Peregrinaciones y procesiones rituales en los Andes. En Adivinación y oráculos en el mundo andino antiguo, M. Curatola \& M. Ziolkwski, Eds., pp. 181-204. Lima: Fondo Editorial PUCP-IFEA.

Serna, C., 2009. Proyecto arqueológico Pumacayan: investigación, conservación y puesta en valor. Pumacayan 1 (2): 5 . Huaraz.

Serna, C., 2009. Proyecto Arqueológico Pumacayan: investigación, conservación y puesta en valor. Pumacayan 1 (4): 13-14. Huaraz. 
Tantaleán, H. \& C. Pérez, 2003. Pueblo Viejo. Un centro administrativo inca en el Callejón de Huaylas. En Arqueología de la sierra de Ancash. Propuestas y perspectivas. B. Ibarra, Ed., pp. 445-456. Lima: Instituto Cultural RvNA.

VARón, R., 1980. Curacas y encomenderos. Acomodamiento nativo en Huaraz, siglos XVI y XVII. Lima: P. L. Villanueva.

VARÓN, R., 1993. Estrategias políticas y relaciones conyugales. El comportamiento de incas y españoles en Huaylas en la primera mitad del siglo Xvi. Boletín del Instituto Francés de Estudios Andinos 22 (3): 721-737.

Villanueva. R., 2011. Características de la cuenca del río Santa. Folleto Informativo 1. Unión Internacional para la Conservación de la Naturaleza, Instituto de Montaña Huaraz. <http://mountain.pe/wp-content/uploads/2012/02/ Folleto-1-Caracteristicas-Cuenca-Rio-Santa.pdf $>$ [Citado 15-08-2017].
VITRY, C., 2002. Apachetas y mojones, marcadores espaciales del paisaje prehispánico. Revista 1 Escuela de Historia 1: $179-191$.

VITRY, C., 2007. Caminos rituales y montañas sagradas. Estudio de la vialidad inka en el nevado de Chañi, Argentina. Boletín del Museo de Chileno de Arte Precolombino 12 (2): 69-84.

ZuloAgA, M., 2011. Las encomiendas y el poder local en Huaylas: las guarangas en la construcción del sistema colonial. Diálogo Andino 37: 67-86.

ZuloagA, M., 2012. La conquista negociada: guarangas, autoridades locales e imperio en Huaylas, Perú (1532-1610). Lima: IFEA-IEP. 